\title{
The Nature of the Renal
}

\section{Adaptation to Chronic Hypocapnia}

\author{
F. John Gennari, Marc B. Goldstein, and William B. Schwartz \\ From the Department of Medicine, Tufts University School of Medicine, and \\ the Renal Laboratory of the New England Medical Center Hospitals, \\ Boston, Massachusetts 02111
}

A B S T R A C T Metabolic balance studies were carried out in normal dogs to define the renal mechanisms responsible for the adaptation to, and recovery from, chronic hypocapnia. A chronic reduction in arterial $\mathrm{CO}_{2}$ tension $\left(\mathrm{Paco}_{2}\right)$ of some $15 \mathrm{~mm} \mathrm{Hg}$ was achieved by means of chronic exposure of the animals to $9 \%$ oxygen in an environmental chamber. The development of hypocapnia was associated with a marked suppression of net acid excretion which, together with a slight accumulation of organic acids, produced a reduction in plasma bicarbonate concentration $(8 \mathrm{mEq} / \mathrm{liter})$ that led to nearly full protection of extracellular $\mathrm{pH}\left(\Delta \mathrm{H}^{+}=\right.$ -2.5 nmoles/liter). When $\mathrm{Paco}_{2}$ was returned to control levels, an augmentation of acid excretion restored plasma composition to normal after a brief period of "posthypocapneic metabolic acidosis."

The changes in renal acid excretion during both adaptation and recovery were accomplished in a fashion notably different from that previously observed in chronic hypercapnia, being linked to changes in cation rather than chloride excretion. Thus, in dogs ingesting a normal $\mathrm{NaCl}$ diet, suppression of hydrogen ion excretion during adaptation to hypocapnia was associated with an increased excretion of sodium rather than with a retention of chloride. The fact that this loss of sodium occurred without a concomitant loss of potassium strongly suggests that the hypocapneic state specifically depressed distal sodium reabsorption; if distal sodium reabsorption had not been depressed, a reduction in proximal sodium reabsorption or a diminution in distal hydrogen ion

Dr. Gennari is the recipient of a Postdoctoral Fellowship from the National Institutes of Health. Dr. Goldstein is the recipient of a Postdoctoral Fellowship from the Medical Research Council of Canada.

A preliminary report of this work was published in abstract form in 1971, Clin. Res. 19: 511.

Received for publication 24 November 1971 and in revised form 2 February 1972. secretion (or both) should have produced an increase in potassium excretion.

The interpretation that chronic hypocapnia diminished sodium reabsorption was supported by the finding that when renal sodium avidity was enhanced by restriction of sodium intake, acid retention was accomplished by a loss of potassium rather than of sodium. The accompanying reduction in plasma bicarbonate concentration was slightly less than that observed in dogs ingesting a normal $\mathrm{NaCl}$ diet, a finding probably accounted for by a slight difference in the availability of cation for excretion under the two experimental circumstances. These findings, taken together with the observation that augmented acid excretion during recovery from hypocapnia is linked to cation retention, suggest that an adequate intake of cation during both adaptation and recovery from chronic hypocapnia may be critical to the physiologic regulation of acid-base equilibrium.

\section{INTRODUCTION}

A variety of studies have delineated the renal adjustments responsible for the defense of $\mathrm{pH}$ in chronic hypercapnia (1-4), but nothing is known of the mechanisms that account for the adaptation to chronic hypocapnia. In the present study we have attempted to characterize the renal regulation of acid-base equilibrium in chronic hypocapnia by means of detailed metabolic observations in dogs exposed to low oxygen tensions in an environmental chamber.

Our data demonstrate that the tubular transport mechanisms linked to changes in acid excretion during both adaptation and recovery are notably different from those encountered in chronic hypercapnia. During a sustained reduction of $\mathrm{Paco}_{2}$, the adaptive changes in acid excretion were accomplished by a loss of cation rather than a retention of chloride. Similarly, during re- 
covery from hypocapnia, increased acid excretion was linked to a retention of cation without a change in chloride balance. These findings suggest that dietary cation intake may importantly influence the renal acidbase adjustments in chronic hypocapnia just as dietary chloride intake influences the renal response during recovery from chronic hypercapnia.

\section{METHODS}

Studies were carried out on 22 female mongrel dogs in an environmental chamber (5) that allows the percentage of oxygen in the atmosphere to be controlled automatically within $\pm 0.5 \%$. Hyperventilation and hypocapnia were induced by decreasing the percentage of oxygen in the chamber, using nitrogen as a diluent. To prevent the expired carbon dioxide from accumulating in the atmosphere, the air in the chamber was continuously recirculated through a carbon dioxide removal system capable of maintaining the ambient carbon dioxide concentration in the chamber at less than $0.3 \%$ for extended periods. The $\mathrm{CO}_{2}$ scrubber is described in detail at the end of the Methods section.

The dogs were fed $30 \mathrm{~g} / \mathrm{kg}$ of an artificial diet (1) homogenized with twice its weight of water. The intrinsic electrolyte content of the diet was as follows: sodium, less than $1 \mathrm{mEq} / 100 \mathrm{~g}$; potassium, less than $0.1 \mathrm{mEq} / 100 \mathrm{~g}$; and chloride, less than $1 \mathrm{mEq} / 100 \mathrm{~g}$. This diet was supplemented with neutral potassium phosphate, $2.5 \mathrm{mEq} / \mathrm{kg}$ of body weight. The control weights of the dogs ranged from 10 to $20 \mathrm{~kg}$ (average weight, $14 \mathrm{~kg}$ ).

Two groups were studied: (a) A normal $\mathrm{NaCl}$ group (10 dogs) in which the diet was also supplemented with 2.5 $\mathrm{mEq} / \mathrm{kg}$ of sodium chloride, and (b) a low $\mathrm{NaCl}$ group (12 dogs) in which no sodium chloride was added to the diet. Dogs that did not eat were tube fed twice daily and dogs that vomited were excluded from further study. Metabolic balance studies were carried out in 14 dogs ( 7 normal $\mathrm{NaCl}$ and 7 low $\mathrm{NaCl}$ ) ; in the remaining 8 dogs, only observations on plasma composition were made.

\section{Experimental design}

The experiments were divided into three periods: control, hypocapnia, and (for the normal $\mathrm{NaCl}$ group only) recovery.

Control. Dogs were maintained in an environment of normal room air for a period of 5-8 days before the induction of hypoxemia and hypocapnia. At least four arterial blood samples were obtained during this period of observation.

Hypocapnia. The percentage of oxygen in the atmosphere was decreased from 21 to $9 \%$ in a stepwise fashion over a period of 4-5 days. This process of acclimatization was employed because in preliminary studies a reduction in oxygen concentration to $9 \%$ over a shorter period $(24-48 \mathrm{hr}$ ) almost invariably led to vomiting and prostration. After acclimatization the dogs were maintained in a 9\% oxygen atmosphere for 1-2 wk. During this time at least four arterial blood samples were obtained.

Recovery (Normal NaCl group only). Restoration of a normal $\mathrm{PaCO}_{2}$ was accomplished by increasing the oxygen concentration to normal in a stepwise fashion over a period of 4-8 hr. Studies were then continued for an additional period of at least 5 days.

\section{Analytical methods}

The analytical methods used to determine $\mathrm{pH}$, total $\mathrm{CO}_{2}$ content, oxygen saturation, and lactate have been described previously $(6,7)$, as have the methods used for the balance technique in this laboratory (8). The $\mathrm{pH}, \mathrm{pK}^{\prime}$, and solubility coefficient of $\mathrm{CO}_{2}$ were corrected to the temperature of the dogs (which was measured by rectal thermometer at the time each blood sample was taken) employing the data of Rosenthal (9) and Severinghaus, Stupfel, and Bradley $(10,11)$. The arterial $\mathrm{P}_{\mathrm{O}_{2}}$ was calculated from the observed oxygen saturation, using the hemoglobin dissociation curve for the $\operatorname{dog}(12)$.

\section{Carbon dioxide scrubber}

The $\mathrm{CO}_{2}$ scrubbing apparatus utilizes a sodium hydroxide solution to continuously remove carbon dioxide from the chamber atmosphere. The apparatus consists of two caustic towers (total capacity, $5 \frac{1}{2} \mathrm{ft}^{3}$ ) placed over a 200 gallon recirculating tank containing a $2 \mathrm{~N} \mathrm{NaOH}$ solution. During operation of the system the $\mathrm{NaOH}$ solution is continuously pumped from the bottom of the recirculating tank to the top of the caustic towers at a rate of approximately 4 gallons per min. At the same time air from the environmental chamber is circulated by a blower through each of the towers (in series) at a rate of $50 \mathrm{ft}^{3} / \mathrm{min}$. The towers are filled with a packing of polypropylene rings in order to increase the area of contact between the caustic solution and circulating air. After exposure to the $\mathrm{NaOH}$ solution, the air is passed through a water wash system to remove the caustic vapor and then through a cooling system to remove excess moisture. It is subsequently reheated to room temperature and returned to the chamber.

At the termination of each study the recirculating tank is drained and flushed with water to remove accumulated $\mathrm{Na}_{2} \mathrm{CO}_{3}$. With six to eight dogs in the chamber, an initial volume of 150 gallons of $2 \mathrm{~N} \mathrm{NaOH}$ solution was found to be more than sufficient to keep the chamber atmosphere at a $\mathrm{CO}_{2}$ level of less than $0.3 \%$ for a 3 wk period of study.

\section{RESULTS}

Exposure to $9 \%$ oxygen produced a reduction in mean arterial oxygen tension to $40 \mathrm{~mm} \mathrm{Hg}$ in the normal $\mathrm{NaCl}$ group and to $38 \mathrm{~mm} \mathrm{Hg}$ in the low $\mathrm{NaCl}$ group. None of the dogs showed untoward effects during the period of hypoxemia and hypocapnia; no change in motor activity was noted, and the animals appeared alert and in most instances ate their diets spontaneously.

Fig. 1 presents the sequence of changes in plasma composition during adaptation to and recovery from hypocapnia for a representative study of a dog on a normal $\mathrm{NaCl}$ intake. During the first 5 days of hypocapnia the fall in $\mathrm{Paco}_{2}$ was associated with a decrease in plasma bicarbonate concentration of $7 \mathrm{mEq} /$ liter and an increase in chloride concentration of $5 \mathrm{mEq} /$ liter; there was only a slight decrease in hydrogen ion concentration ( 2 nmoles/liter). During the subsequent 11 days of hypocapnia, the bicarbonate, chloride, and hydrogen ion concentrations and plasma $\mathrm{CO}_{2}$ tension remained virtually constant. In the recovery phase, the $\mathrm{Paco}_{2}$ increased rapidly to the normal range, but the 


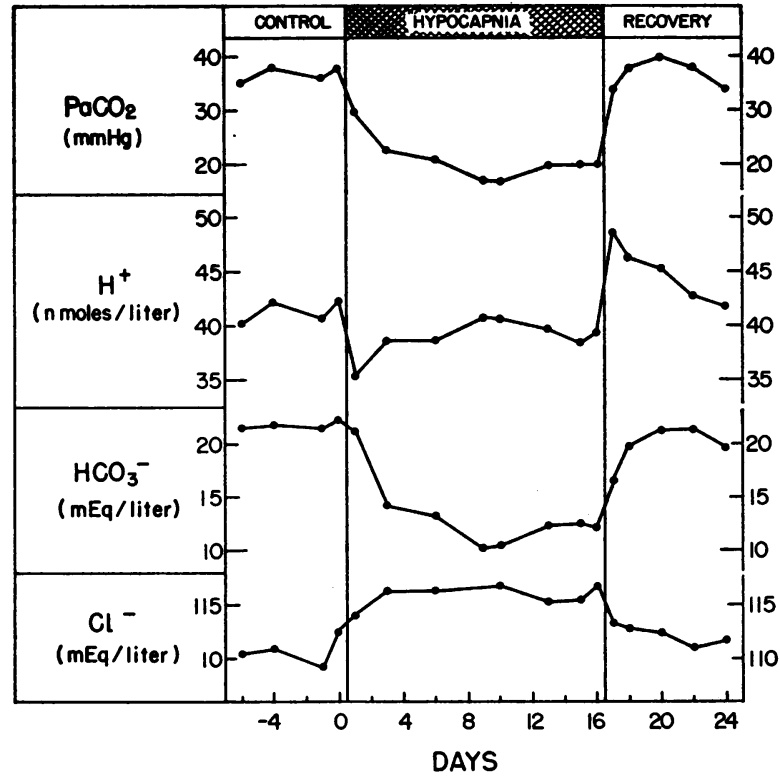

FIgURE 1 Changes in plasma acid-base composition during adaptation and recovery from hypocapnia in a representative dog on a normal $\mathrm{NaCl}$ intake (No. 156). The fall in $\mathrm{PacO}_{2}$ was induced over the first 5 days of the hypocapnia period by stepwise decrements in atmospheric oxygen concentration to a final value of $9 \%$. On day 16 , the ambient oxygen concentration was returned to normal over a period of $8 \mathrm{hr}$.

plasma bicarbonate concentration increased more gradually, returning to the normal range only after 4-5 days. As a result, the animal developed a transient acidosis (lowest $\mathrm{pH}, 7.31$ ).

\section{Evidence for a Steady-State}

Statistical analysis of observations from all experiments (both normal and low $\mathrm{NaCl}$ ) demonstrated no significant trend in either $\mathrm{Paco}_{2}$ or plasma bicarbonate concentration from the first day at $9 \%$ oxygen (5th day of the hypocapnia period) to the end of the period of exposure (7-14 days). During the steady-state period of hypocapnia (5th day to end of period) the maximum deviation of $\mathrm{Paco}_{2}$ from the mean value for the period was $3 \mathrm{~mm} \mathrm{Hg}$, and the maximum deviation of plasma bicarbonate concentration was less than $2 \mathrm{mEq} /$ liter.

\section{Plasma Changes during Steady-State Hypocapnia}

Normal $\mathrm{NaCl}$ group (10 dogs). Fig. 2 presents the steady-state $\mathrm{Paco}_{2}$, plasma bicarbonate and hydrogen ion concentrations before and during exposure to $9 \%$ oxygen. The mean steady-state values for each dog were calculated for both the control and hypocapnia period from the last four plasma determinations during each period. As can be seen in the figure, and in the upper portion of
Table I, mean $\mathrm{Paco}_{2}$ fell from 36 to $21 \mathrm{~mm} \mathrm{Hg}$, plasma bicarbonate concentration from 21 to $13 \mathrm{mEq} /$ liter, and hydrogen ion concentration from 42 to 39.5 nmoles/liter $(P<0.01$ in each case). The mean plasma chloride concentration increased from 111 to $117 \mathrm{mEq} /$ liter. No notable change occurred in either sodium or potassium concentration.

Low $\mathrm{NaCl}$ group (12 dogs). Fig. 3 presents the steady-state $\mathrm{Paco}_{2}$, bicarbonate, and hydrogen ion concentrations before and during exposure to $9 \%$ oxygen. The mean steady-state values for each dog were calculated in the same manner as described above for the normal $\mathrm{NaCl}$ group. As can be seen in this figure, and in the lower portion of Table I, mean $\mathrm{Paco}_{2}$ fell from 36 to $24 \mathrm{~mm} \mathrm{Hg}$, plasma bicarbonate concentration from 22 to $16 \mathrm{mEq} /$ liter, and hydrogen ion concentration from 41 to 37 nmoles/liter $(P<0.01$ in each case $)$. It is noteworthy that although the mean $\mathrm{Paco}_{2}$ in the low $\mathrm{NaCl}$ group was $3 \mathrm{~mm} \mathrm{Hg}$ higher than in the normal $\mathrm{NaCl}$ group during the hypocapnia period $(P<0.01)$, the hydrogen ion concentration in the low $\mathrm{NaCl}$ group was 2.4 nmoles/liter lower $(P<0.01)$. No notable changes
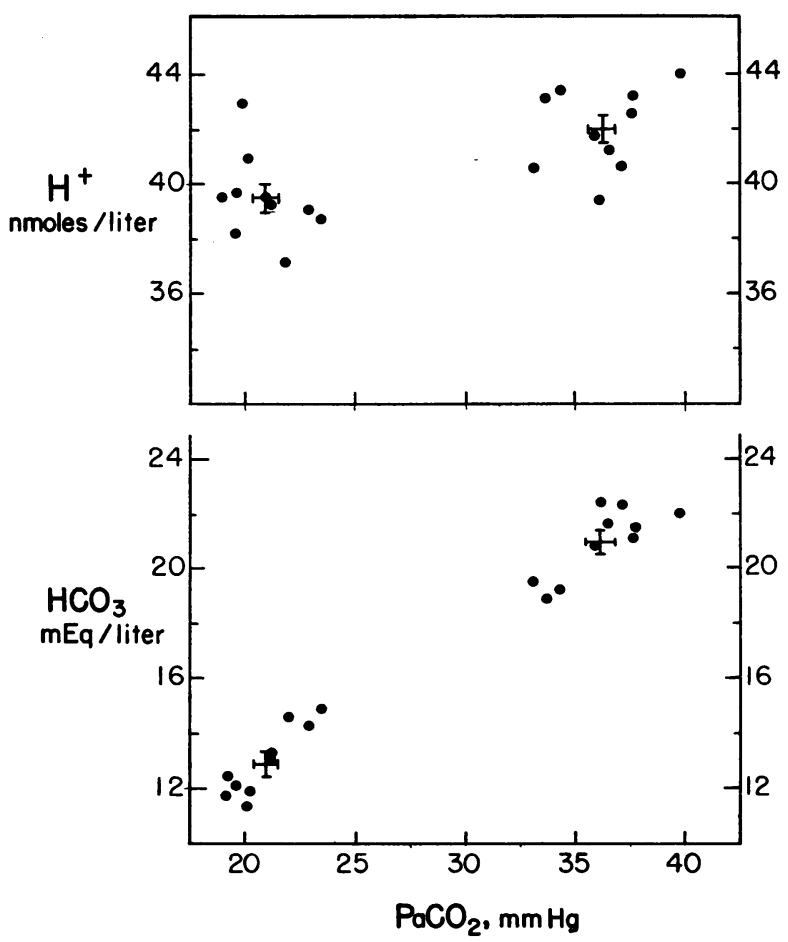

Figure 2 Steady-state relationship between $\mathrm{Paco}_{2}$ and plasma hydrogen ion concentration (upper panel) and plasma bicarbonate concentration (lower panel) during normocapnia and chronic hypocapnia in dogs on a normal $\mathrm{NaCl}$ intake. Each point on the graph represents the mean of the last four plasma determinations during each period of observation. The cross bars indicate the mean control and hypocapnia values $( \pm 1 \mathrm{SE})$ for the group. 
TABLE I

Plasma Composition in Chronic Hypocapnia*

\begin{tabular}{|c|c|c|c|c|c|c|c|}
\hline & $\mathrm{PaCO}_{2}$ & $\mathbf{H}$ & $\mathrm{HCO}_{2}$ & $\mathrm{Na}$ & $\mathbf{K}$ & $\mathbf{C l}$ & Anion gap \\
\hline & $m m \mathrm{Hg}$ & nmoles/liter & $m E q /$ liter & $m E q /$ liter & $m E q /$ liter & $m E q /$ liter & $m E q /$ liter \\
\hline \multicolumn{8}{|c|}{ Normal $\mathrm{NaCl}$ group } \\
\hline $\begin{array}{l}\text { Control } \\
\text { Hypocapnia }\end{array}$ & $\begin{array}{l}36 \pm 0.6 \ddagger \\
21 \pm 0.5 \ddagger\end{array}$ & $\begin{array}{l}42.0 \pm 0.5 \ddagger \\
39.5 \pm 0.5 \ddagger\end{array}$ & $\begin{array}{l}21.0 \pm 0.4 \ddagger \\
12.9 \pm 0.4 \ddagger\end{array}$ & $\begin{array}{l}147 \pm 0.6 \\
146 \pm 0.8\end{array}$ & $\begin{array}{l}3.8 \pm 0.1 \\
3.9 \pm 0.1\end{array}$ & $\begin{array}{l}111 \pm 0.6 \ddagger \\
117 \pm 1.1 \ddagger\end{array}$ & $\begin{array}{l}18 \pm 0.5 \ddagger \\
21 \pm 0.6 \ddagger\end{array}$ \\
\hline \multicolumn{8}{|c|}{ Low $\mathrm{NaCl}$ group } \\
\hline $\begin{array}{l}\text { Control } \\
\text { Hypocapnia }\end{array}$ & $\begin{array}{l}36 \pm 0.6 \ddagger \\
24 \pm 0.4 \ddagger\end{array}$ & $\begin{array}{l}41.1 \pm 0.5 \ddagger \\
37.1 \pm 0.6 \ddagger\end{array}$ & $\begin{array}{l}21.6 \pm 0.4 \ddagger \\
15.7 \pm 0.5 \ddagger\end{array}$ & $\begin{array}{l}144 \pm 0.5 \ddagger \\
142 \pm 0.7 \ddagger\end{array}$ & $\begin{array}{l}4.2 \pm 0.1 \\
4.2 \pm 0.1\end{array}$ & $\begin{array}{l}108 \pm 0.6 \\
109 \pm 0.9\end{array}$ & $\begin{array}{l}19 \pm 0.5 \ddagger \\
22 \pm 0.5 \ddagger\end{array}$ \\
\hline
\end{tabular}

* Values shown are the means \pm 1 standard error.

‡ Denotes that the difference between mean control value and mean value during chronic hypocapnia is significant at a value of $P<0.01$.

occurred in either plasma chloride or potassium concentration. Plasma sodium concentration decreased by 2 $\mathrm{mEq} /$ liter.

\section{Plasma Changes during Recovery from HYPOCAPNIA}

The six normal $\mathrm{NaCl}$ dogs studied during the recovery phase all behaved in a similar fashion to the dog illustrated in Fig. 1. The mean plasma bicarbonate con-

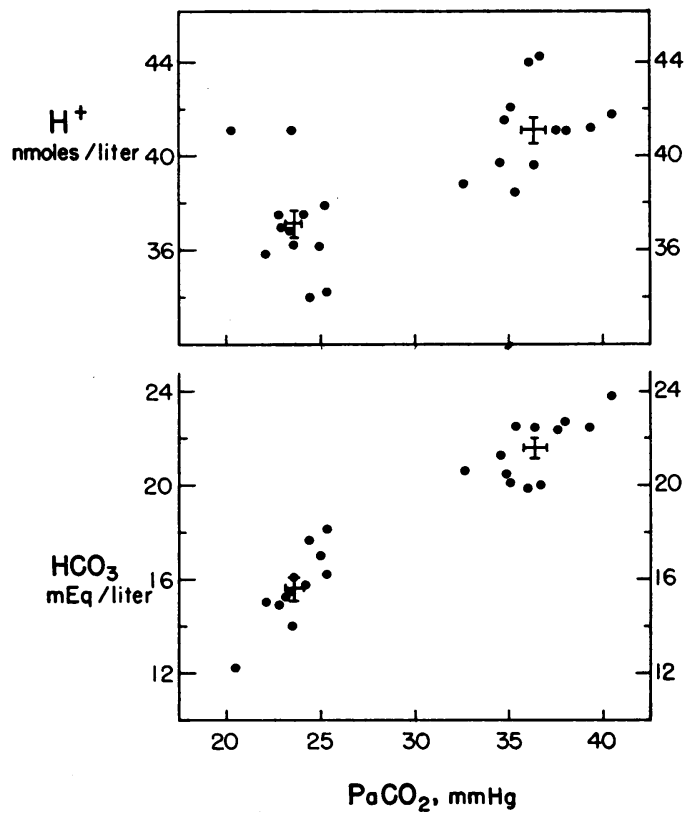

FIgURe 3 Steady-state relationship between $\mathrm{Paco}_{2}$ and plasma hydrogen ion concentration (upper panel), and plasma bicarbonate concentration (lower panel) during normocapnia and hypocapnia in dogs on a low $\mathrm{NaCl}$ diet. Each point on the graph represents the mean of the last four plasma determinations during each period of observation. The crossbars indicate the mean control and hypocapnia values $( \pm 1 \mathrm{SE})$ for the group. centration was $15.7 \mathrm{mEq} /$ liter on the day after return to a normal atmospheric environment, $5 \mathrm{mEq} /$ liter less than the mean control value before exposure to hypocapnia $(P<0.01)$. As a result, five of the six dogs developed a transient acidosis (mean plasma $\mathrm{H}^{+}=48$ nmoles/ liter); the remaining dog had a normal plasma hydrogen ion concentration due to persistent hyperventilation. Over the next several days the mean plasma bicarbonate concentration returned virtually to normal, reaching a value of $19.3 \mathrm{mEq} /$ liter on the 4th day as compared to a control value of $20.7 \mathrm{mEq} /$ liter.

\section{Miscellaneous}

In both the normal $\mathrm{NaCl}$ group and the low $\mathrm{NaCl}$ group, the unmeasured anion concentration $(\mathrm{Na}+\mathrm{K}-$ $\left.\left[\mathrm{HCO}_{3}+\mathrm{Cl}\right]\right)$ increased by $3 \mathrm{mEq} /$ liter during the period of hypocapnia (Table I). Since plasma hydrogen ion concentration changed only slightly during hypocapnia, this increase in unmeasured anions cannot be accounted for on the basis of a titration of blood buffers such as phosphate or protein; it therefore must have reflected an accumulation of organic anions, the source of which remains unclear. The only evidence at hand is that lactate accumulation (measured in three dogs in the normal $\mathrm{NaCl}$ group and in six dogs in the low $\mathrm{NaCl}$ group) did not contribute significantly; the mean plasma lactate concentration was $2.2 \mathrm{mmoles} /$ liter during hypocapnia as opposed to a control value of 2.0 mmoles/liter. ${ }^{1}$

Plasma phosphate concentration increased slightly from a mean value of 1.4 to 1.7 mmoles/liter during hypocapnia in the normal $\mathrm{NaCl}$ group $(P<0.01)$; no change was observed in the low $\mathrm{NaCl}$ group. The mean hemato-

\footnotetext{
${ }^{1}$ It is noteworthy that an almost identical increase in unmeasured anions not related to a rise in lactate concentration, also occurs in dogs with normocapneic hypoxemia (13). This finding suggests that the increase in unmeasured anions observed in the present study may have occurred in response to hypoxemia rather than hypocapnia.
} 
crit increased from 46 to $55 \%$ in the normal $\mathrm{NaCl}$ group, and from 50 to $58 \%$ in the low $\mathrm{NaCl}$ group $(P<0.01$ in both instances $)$.

\section{Balance data \\ Changes in Urinary Acid Excretion during Adaptation to Hypocapnia}

The cumulative changes in urinary net acid excretion (estimated as differences from the mean daily control excretion) during the first 5 days of hypocapnia for all experiments are presented in Fig. 4 and in Tables II and III. The first 5 days of study were chosen because all of the noteworthy changes in both plasma acid-base composition and urinary acid excretion occurred during this interval. Cumulative net acid excretion decreased in the normal $\mathrm{NaCl}$ group by a mean value of $37 \mathrm{mEq}$, and in the low $\mathrm{NaCl}$ group by $42 \mathrm{mEq}(P<0.01$ in both cases). The major portion of this change could be accounted for by a decrease in ammonium excretion in both groups ( 28 and $30 \mathrm{mEq}$, respectively). The remainder of the fall in net acid excretion was due to a decrease in titratable acidity; no significant bicarbonate loss was noted.

Changes in Electrolyte and Nitrogen Balance during Adaptation to Hypocapnia

The cumulative changes in urinary electrolyte excretion during adaptation to hypocapnia are presented in Fig. 4; the changes in electrolyte and nitrogen balance are presented in Tables II and III. Just as in the case of net acid excretion, all of the notable changes in urinary electrolyte excretion were found during the first 5 days of study. As shown in the left-hand panel of Fig. 4, in the normal $\mathrm{NaCl}$ group there was no significant change in either urinary chloride or potassium excretion, but there was a mean cumulative loss of sodium of $35 \mathrm{mEq}(P<0.02)$. In the low $\mathrm{NaCl}$ group (right-hand panel of Fig. 4), no significant changes were observed in either urinary chloride or sodium excretion, but there was a mean cumulative loss of potassium of $28 \mathrm{mEq}(P<0.01)$.

No notable changes in fecal electrolyte excretion occurred and therefore the changes in electrolyte balance almost precisely reflected the changes in urinary electrolyte excretion (Tables II and III). No significant changes in nitrogen balance were noted in either the normal or low $\mathrm{NaCl}$ groups. Urinary phosphate excretion during the first 5 days of hypocapnia decreased slightly as compared to control $(-11$ and -21 mmoles in the normal and low $\mathrm{NaCl}$ groups, respectively). Urinary sulfate excretion, measured in two dogs on a normal $\mathrm{NaCl}$ intake, showed no notable changes.

\section{RECOVERY FROM HYPOCAPNIA}

The changes in electrolyte and in acid excretion in the six normal $\mathrm{NaCl}$ dogs studied during recovery from hypocapnia are presented in Fig. 5, and the changes in balance in Table II. During the first 5 days, over which plasma composition returned virtually to normal, acid excretion increased by a mean value of $50 \mathrm{mEq}$ and there was a sodium retention of $38 \mathrm{mEq}(P<0.01$ in
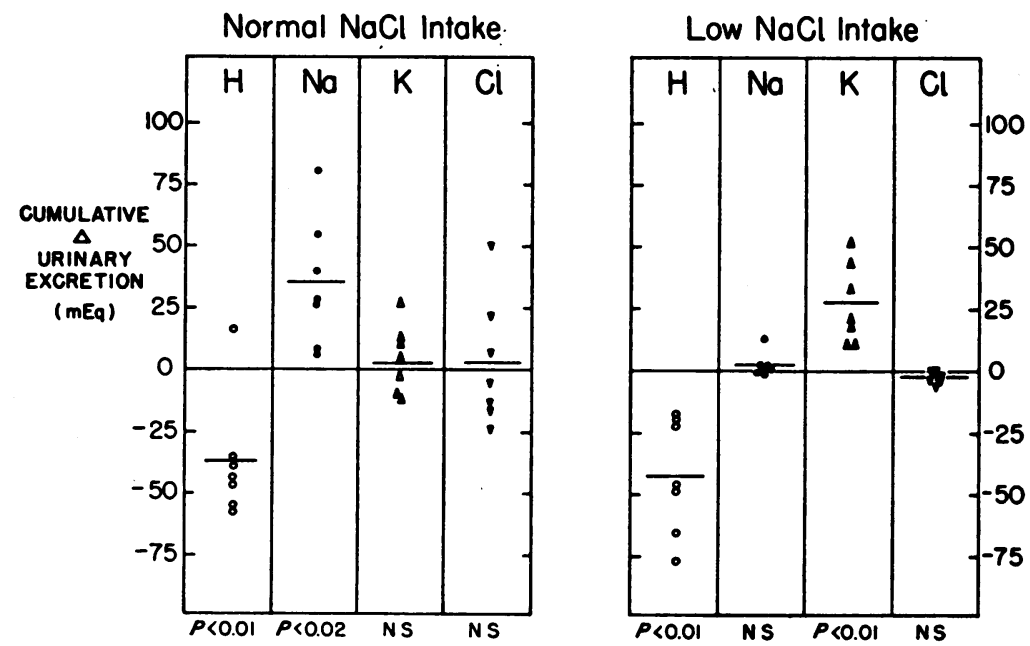

FIGURE 4 Cumulative changes in urinary net acid and electrolyte excretion (as compared to the mean daily control excretions) during the first 5 days of hypocapnia in the normal $\mathrm{NaCl}$ group (left hand panel) and in the low $\mathrm{NaCl}$ group (right hand panel). The horizontal solid line in each panel indicates the mean value for the group. The significance level of the difference between the mean value and zero is indicated below each panel. 
TABLE II

Cumulative Changes in Electrolyte Balance and Net Acid

Excretion in the Normal NaCl Group during the First 5 Days of Hypocapnia and the First 5 Days of Recovery*

\begin{tabular}{|c|c|c|c|c|c|c|}
\hline Dog & $\mathbf{N a}$ & $\mathrm{Cl}$ & $\mathbf{K}$ & $\mathbf{N}$ & Knf & $\begin{array}{l}\text { Net } \\
\text { acid }\end{array}$ \\
\hline & $m E q$ & $m E q$ & $m E q$ & 8 & $m E q$ & $m E q$ \\
\hline \multicolumn{7}{|c|}{ A. Hypocapnia } \\
\hline 553 & -56 & -27 & -10 & -4 & 1 & -44 \\
\hline 554 & 6 & 19 & 10 & 1 & 8 & -55 \\
\hline 555 & -87 & -9 & -15 & -5 & -3 & -38 \\
\hline 560 & -18 & -15 & 3 & 1 & 2 & -37 \\
\hline 154 & -79 & -52 & -24 & -8 & -6 & 16 \\
\hline 156 & -14 & 15 & 8 & 1 & 5 & -46 \\
\hline 157 & -25 & 13 & 8 & 1 & 5 & -57 \\
\hline Average & -39 & -8 & -3 & -2 & 2 & -37 \\
\hline \multicolumn{7}{|c|}{ B. Recovery } \\
\hline 553 & 16 & -12 & -4 & -5 & 8 & 69 \\
\hline 554 & 51 & -1 & 9 & 3 & 2 & 46 \\
\hline 560 & 43 & 9 & 9 & 2 & 4 & 25 \\
\hline 154 & 47 & 17 & 10 & -2 & 10 & 60 \\
\hline 156 & 42 & -2 & 5 & 2 & -1 & 39 \\
\hline 157 & 31 & -1 & -7 & -3 & 1 & 61 \\
\hline Average & 38 & 2 & 4 & -1 & 4 & 50 \\
\hline
\end{tabular}

* Changes from control have been cumulated separately for each period.

$\ddagger \mathrm{K} \mathbf{n}=\mathrm{K}$ corrected for $\mathrm{N}$.

each case). These changes are approximately equal and opposite in direction to those seen during adaptation to hypocapnia. There was no significant change in chloride, potassium, or nitrogen balance.

\section{TABLE III}

Cumulative Changes in Electrolyte Balance and Net Acid Excretion in the Low $\mathrm{NaCl}$ Group during the First 5 Days of Hypocapnia

\begin{tabular}{crrrrrr}
\hline Dog & $\mathrm{Na}$ & $\mathrm{Cl}$ & $\mathrm{K}$ & $\mathrm{N}$ & $\mathrm{Kn}^{*}$ & $\begin{array}{c}\text { Net } \\
\text { acid }\end{array}$ \\
\hline Hypocapnia & $m E q$ & $m E q$ & $m E q$ & $\mathrm{~g}$ & $m E q$ & $m E q$ \\
251 & -7 & 6 & -32 & -4 & -21 & -22 \\
257 & -1 & 9 & -9 & 1 & -13 & -48 \\
259 & -7 & 2 & -42 & -5 & -30 & -18 \\
261 & 7 & 8 & -39 & 1 & -38 & -78 \\
269 & -12 & 3 & -7 & 4 & -22 & -46 \\
270 & 1 & 8 & -34 & 4 & -51 & -19 \\
272 & -13 & -3 & -23 & 7 & -41 & -65 \\
Average & -5 & 5 & -27 & 1 & -31 & -42 \\
\hline
\end{tabular}

$* \mathrm{~K} n=\mathrm{K}$ corrected for $\mathrm{N}$.

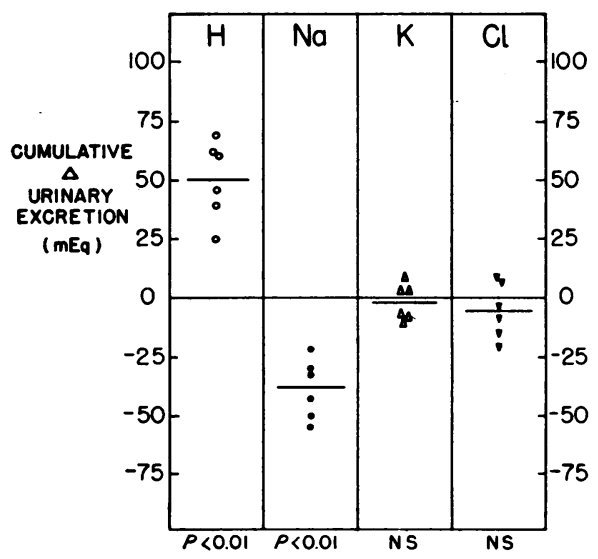

FIgURE 5 Cumulative changes in urinary net acid and electrolyte excretion (as compared to the mean daily control excretions) during the first 5 days of recovery from chronic hypocapnia in the normal $\mathrm{NaCl}$ group. The horizontal solid line in each panel indicates the mean value for the group. The significance level of the difference between the mean value and zero is indicated below each panel.

The rise in plasma chloride concentration during adaptation and the fall during recovery, both of which occurred without a concomitant change in chloride balance, are presumably the result of a slight contraction in extracellular fluid volume when sodium was lost during the adaptive phase and a subsequent reexpansion as sodium was retained after $\mathrm{Paco}_{2}$ was returned to normal.

\section{DISCUSSION}

The present study has demonstrated that the defense of $\mathrm{pH}$ during adaptation to chronic hypocapnia is accomplished largely by a suppression of urinary net acid excretion. As can be seen in Fig. 4, in dogs ingesting a normal $\mathrm{NaCl}$ diet a $15 \mathrm{~mm} \mathrm{Hg}$ reduction in $\mathrm{Paco}_{2}$ typically led to a $40-50 \mathrm{mEq}$ decrease in acid excretion. This retention of hydrogen ion was far in excess of the amount necessary to account for the fall in extracellular bicarbonate concentration and was almost sufficient to account for an equivalent reduction in intracellular alkali stores. A slight accumulation of organic acids, as reflected by a $3 \mathrm{mEq} /$ liter increase in unmeasured anions, made a small additional contribution to the reduction in body buffer stores.

Although the defense of $\mathrm{pH}$ in both chronic hypocapnia and chronic hypercapnia is achieved by changes in renal acid excretion, the way in which hydrogen ion balance is altered in these two states is markedly different. In chronic hypercapnia the alterations in acid excretion are linked to parallel changes in chloride excretion $(1,2)$, whereas in chronic hypocapnia they are accomplished by reciprocal changes in cation balance. Thus, during adaptation to hypocapnia in dogs ingesting a normal $\mathrm{NaCl}$ diet there was no significant 
change in chloride excretion, the renal retention of hydrogen ion being linked instead to an increase in sodium excretion (Fig. 4). ${ }^{2}$ Similarly, during the recovery phase, when $\mathrm{Paco}_{2}$ was returned to normal, there was an augmentation of acid excretion that was accompanied by a nearly equal retention of sodium (Fig. 5).

The observation that the retention of hydrogen ion during adaptation to chronic hypocapnia was associated with an increase in sodium excretion but not in potassium excretion argues forcefully for the interpretation that the loss of sodium occurred largely if not exclusively as the result of a depression of distal sodium reabsorption. If distal sodium reabsorption had not been depressed, a reduction in distal hydrogen secretion by hypocapnia should have sharply augmented potassium secretion. Furthermore, if a depression of proximal rather than distal sodium reabsorption were responsible for the observed loss of sodium, the increased delivery of sodium to the distal nephron should in itself have led to an acceleration of potassium transport.

The interpretation that distal sodium reabsorption was specifically depressed by the hypocapneic state gains support from the observation that when tubular sodium conservation was stimulated by prior dietary $\mathrm{NaCl}$ restriction, hydrogen ion retention was then accomplished by a loss of potassium rather than of sodium (Fig. 4). It should be noted, incidentally, that in the NaCl-restricted dogs the plasma bicarbonate concentration fell slightly less and therefore plasma $\mathrm{pH}$ rose slightly more than in animals ingesting a normal $\mathrm{NaCl}$ diet (Table I). This minor degree of impairment of the adaptive response can probably be accounted for by a slight difference in the supply of cation available for excretion in the two experimental circumstances.

Since our data both during adaptation and recovery have clearly demonstrated a close linkage between changes in cation and changes in hydrogen ion excretion, it seems reasonable to speculate that cation availability is critical to the physiologic regulation of acid-base equilibrium in chronic hypocapnia. One might anticipate, for example, that dietary restriction of both sodium and potassium during the period of adaptation would so limit the capacity of the kidney to reduce hydrogen ion excretion, that a marked alkalosis would result. By the

\footnotetext{
${ }^{2}$ In chronic hypoxemia unaccompanied by hypocapnia, there is no significant loss of sodium, nor is there any change in net acid excretion (13). These findings indicate that the changes observed in the present study cannot be attributed to the low oxygen tension per se.

${ }^{3}$ It is of interest that during acute hypocapnia an increase in both potassium secretion (14) and excretion $(15,16)$ have been observed even in the face of a normal $\mathrm{NaCl}$ intake. The fact that our chronic studies have not demonstrated a deficit of potassium when the intake of $\mathrm{NaCl}$ is normal suggests that the losses observed acutely by others were transient.
}

same token it might be expected that dietary cation restriction, begun after adaptation to chronic hypocapnia, would impair the ability of the kidney to augment acid excretion when $\mathrm{Paco}_{2}$ is restored to normal. For example, the animal which has lost sodium during adaptation and is denied access to dietary sodium during the recovery phase might well be expected to develop a sustained posthypocapneic metabolic acidosis, unless, of course, the kidney were suddenly to turn to augmented chloride excretion as a means of correcting the acidosis. ${ }^{4}$

The thesis that selective dietary electrolyte deficits may importantly influence the control of $\mathrm{pH}$ in respiratory acid-base disorders already has considerable support from studies of recovery from chronic hypercapnia. As mentioned earlier, alterations in acid excretion are specifically linked to parallel changes in chloride rather than cation excretion both during adaptation and recovery from hypercapnia; for this reason a restriction of chloride intake during recovery blocks the usual reduction in acid excretion and engenders a sustained posthypercapneic metabolic alkalosis (2). Whether or not cation restriction imposes analogous constraints on the renal regulation of acid-base equilibrium in chronic hypocapnia remains to be determined by further investigation.

As mentioned earlier, our data demonstrate that suppression of acid excretion during adaptation to severe chronic hypocapnia is sufficient to prevent more than a slight decrease in mean plasma hydrogen ion concentration. A reduction of $\mathrm{Paco}_{2}$ to approximately 15-20 $\mathrm{mm} \mathrm{Hg}$ in dogs ingesting a normal $\mathrm{NaCl}$ diet was accompanied by a change of only 2.5 nmoles of hydrogen ion per liter of plasma. Thus, as is not surprising, any single value for hydrogen ion concentration may still lie within the normal range (see 95\% confidence band in Fig. 6). ${ }^{5}$ It follows therefore that in a given animal with chronic hypocapnia, one can confidently expect to detect the rise in $\mathrm{pH}$ only when a control observation is available.

A comparison of our data with those obtained in man after 1-4 wk of hypocapnia suggest that the defense of $\mathrm{pH}$ in man is less effective than in the dog. In all studies

\footnotetext{
'It should be noted, incidentally, that even when liberal quantities of sodium were available in the diet during the recovery phase, the physiologic lag in augmenting acid excretion delayed the recovery process and led to a transient state of posthypocapneic metabolic acidosis (Fig. 1).

${ }^{5}$ The statistical methods used to compute the range of values for these significance bands have been described previously (4). In constructing the bands, we have assumed that the relationship between $\mathrm{H}^{+}$and $\mathrm{Paco}_{2}$ is linear over the range of carbon dioxide tensions studied. This assumption seems reasonable, first, because the range of $\mathrm{Paco}_{2}$ levels is relatively narrow $(15-40 \mathrm{~mm} \mathrm{Hg})$, and second, because the observed changes in hydrogen ion concentration are small.
} 

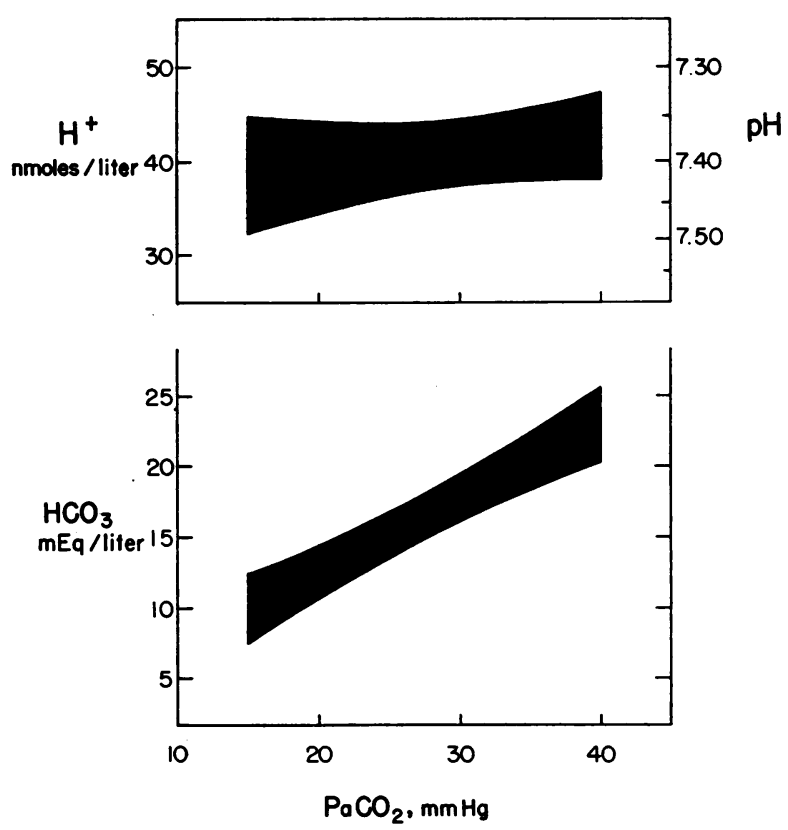

FigURE 6 Significance bands for plasma hydrogen ion and bicarbonate concentration in chronic hypocapnia. In uncomplicated chronic hypocapnia in the dog, a single new observation of hydrogen ion and bicarbonate concentration will, with an estimated $95 \%$ probability, fall within the respective zones. The technique employed in the calculation of these significance bands has been described previously (4).

in man in which control as well as experimental observations were carried out in the same subjects, there was a decrease in hydrogen ion concentration of 5-10 nmoles/ liter when $\mathrm{Pco}_{2}$ was reduced to a range of $20-30 \mathrm{~mm} \mathrm{Hg}$ $(17-20)$. Since this change in hydrogen ion concentration was of sufficient magnitude to carry the values into a frankly alkalotic range, it is rather surprising that in two other studies of hypocapnia of comparable severity and duration, the $\mathrm{pH}$ values were unequivocally normal $(21,22)$; in these latter two studies, however, control observations were not available and the data are therefore difficult to evaluate.

Finally, it should be noted that in the dog the defense of $\mathrm{pH}$ is significantly more effective in chronic hypocapnia than in chronic hypercapnia. Whereas in chronic hypercapnia, the plasma hydrogen ion concentration changes by 0.33 nmoles/liter with each $\mathrm{mm} \mathrm{Hg}$ increase in $\mathrm{Paco}_{2}$ (4), in chronic hypocapnia the change in plasma hydrogen ion concentration is only half as great, i.e., 0.17 nmoles/liter for each millimeter $\mathrm{Hg}$ decrease in $\mathrm{Paco}_{2}$. The explanation for this difference is not clear, but it is conceivable that the disparity may be related to the fact, alluded to earlier, that acid excretion is linked to cation excretion in chronic hypocapnia whereas it is linked to chloride excretion in chronic hypercapnia.
The present data throw no light on this issue nor, at a more fundamental level, do they reveal why different tubular transport mechanisms are linked to acid excretion when $\mathrm{Paco}_{2}$ is elevated as compared to when it is depressed. It is clear, however, that the differences in the physiological response to chronic hypercapnia and hypocapnia pose a problem that merits further investigation.

\section{ACKNOWLEDGMENTS}

We wish to thank Dr. Jonas $H$. Ellenberg for his valuable assistance in the statistical analysis of the data.

This study was supported in part by Grants HE-759 and HE-5309 from the National Heart Institute, National Institutes of Health and the Samuel Bass Fund for Kidney Research.

\section{REFERENCES}

1. Polak, A., G. D. Haynie, R. M. Hays, and W. B. Schwartz. 1961. Effects of chronic hypercapnia on electrolyte and acid-base equilibrium. I. Adaptation. $J$. Clin. Invest. 40 : 1223.

2. Schwartz, W. B., R. M. Hays, A. Polak, and G. D. Haynie. 1961. Effects of chronic hypercapnia on electrolyte and acid-base equilibrium. II. Recovery, with special reference to the influence of chloride intake. $J$. Clin. Invest. 40: 1238.

3. van Ypersele de Strihou, C., P. F. Gulyassy, and W. B. Schwartz. 1962. Effects of chronic hypercapnia on electrolyte and acid-base equilibrium. III. Characteristics of the adaptive and recovery process as evaluated by provision of alkali. J. Clin. Invest. 41: 2246.

4. Schwartz, W. B., N. C. Brackett, Jr., and J. J. Cohen. 1965. The response of extracellular hydrogen ion concentration to graded degrees of chronic hypercapnia: the physiological limits of the defense of $\mathrm{pH}$. J. Clin. Invest. 44: 291.

5. Schwartz, W. B., and L. Silverman. 1965. A large environmental chamber for the study of hypercapnia and hypoxia. J. Appl. Physiol. 20: 767.

6. Goldstein, M. B., F. J. Gennari, and W. B. Schwartz. 1971. The influence of graded degrees of chronic hypercapnia on the acute carbon dioxide titration curve. $J$. Clin. Invest. 50: 208.

7. Arbus, G. S., L. A. Hebert, P. R. Levesque, B. E. Etsten, and W. B. Schwartz. 1969. Characterization and clinical application of the "significance band" for acute respiratory alkalosis. N. Engl. J. Med. 280: 117 .

8. Tannen, R. L., H. L. Bleich, and W. B. Schwartz. 1966. The renal response to acid loads in metabolic alkalosis; an assessment of the mechanisms regulating acid excretion. J. Clin. Invest. 45: 562.

9. Rosenthal, T. B. 1948. The effect of temperature on the $\mathrm{pH}$ of the blood and plasma in vitro. J. Biol. Chem. $173: 25$.

10. Severinghaus, J. W., M. Stupfel, and A. F. Bradley, 1956. Accuracy of blood $\mathrm{pH}$ and $\mathrm{pCO}_{2}$ determinations. J. Appl. Physiol. 9 : 189.

11. Severinghaus, J. W., M. Stupfel, and A. F. Bradley. 1956. Variations of serum carbonic acid $\mathrm{pK}^{\prime}$ with $\mathrm{pH}$ and temperature. J. Appl. Physiol. 9: 197.

12. Rossing, R. G., and S. M. Cain. 1966. A nomogram relating $\mathrm{PO}_{2}, \mathrm{pH}$, temperature, and hemoglobin saturation in the dog. J. Appl. Physiol. 21: 195. 
13. Sapir, D. G., D. Z. Levine, and W. B. Schwartz. 1967. The effects of chronic hypoxemia on electrolyte and acid-base equilibrium: an examination of normocapneic hypoxemia and of the influence of hypoxemia on the adaptation to chronic hypercapnia. J. Clin. Invest. 46: 369.

14. Malnic, G., M. de Mello Aires, and G. Giebisch. 1971. Potassium transport across renal distal tubules during acid-base disturbances. Amer. J. Physiol. 221: 1192.

15. Stanbury, S. W., and A. E. Thomson. 1952. The renal response to respiratory alkalosis. Clin. Sci. (London). 11: 357 .

16. Barker, E. S., R. B. Singer, J. R. Elkinton, and J. K. Clark. 1957. The renal response in man to acute experimental respiratory alkalosis and acidosis. J. Clin. Invest. 36 : 515.

17. Dill, D. B., J. H. Talbott, and W. V. Consolazio. 1937.
Blood as a physiocochemical system. XII. Man at high altitudes. J. Biol. Chem. 118: 649.

18. Houston, C. S., and R. L. Riley. 1947. Respiratory and circulatory changes during acclimatization to high altitude. Amer. J. Physiol. 149 : 565.

19. Severinghaus, J. W., R. A. Mitchell, B. W. Richardson, and M. M. Singer. 1963. Respiratory control at high altitude suggesting active transport regulation of CSF pH. J. Appl. Physiol. 18: 1155.

20. Forwand, S. A., M. Landowne, J. N. Follansbee, and J. E. Hansen. 1968. Effect of acetazolamide on acute mountain sickness. N. Engl. J. Med. 279: 839.

21. Chiodi, H. 1957. Respiratory adaptations to chronic high altitude hypoxia. J. Appl. Physiol. 10: 81.

22. Lahiri, S., and J. S. Milledge. 1967. Acid-base in Sherpa altitude residents and lowlanders at $4880 \mathrm{M}$. Respir. Physiol. 2 : 323. 